\title{
(6) OPEN ACCESS \\ Randomised clinical trial of snus versus medicinal nicotine among smokers interested in product switching
}

\author{
Dorothy K Hatsukami, ${ }^{1,2}$ Herbert Severson, ${ }^{3}$ Amanda Anderson, ${ }^{2}$ \\ Rachael Isaksson Vogel, ${ }^{1}$ Joni Jensen, ${ }^{2}$ Berry Broadbent, ${ }^{3}$ Sharon E Murphy, ${ }^{1}$ \\ Steven Carmella, ${ }^{1}$ Stephen $S$ Hecht ${ }^{1}$
}

\begin{abstract}
- Additional material is published online only. To view please visit the journal online (http://dx.doi.org/10.1136/ tobaccocontrol-2014-052080).

${ }^{1}$ Masonic Cancer Center, University of Minnesota, Minneapolis, Minnesota, USA ${ }^{2}$ Department of Psychiatry, University of Minnesota, Minneapolis, Minnesota, USA ${ }^{3}$ Oregon Research Institute, Eugene, Oregon, USA
\end{abstract}

\section{Correspondence to} Dr Dorothy K Hatsukami, Masonic Cancer Center, University of Minnesota, 717 Delaware St SE, Minneapolis, MN 55414, USA; hatsu001@umn.edu

Received 3 October 2014 Accepted 24 April 2015 Published Online First 19 May 2015

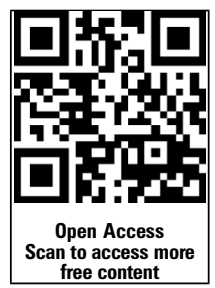

\section{SLinked}

- http://dx.doi.org/10.1136/ tobaccocontrol-2015-052388

\section{CrossMark}

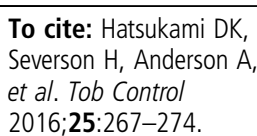

\section{ABSTRACT \\ Background An essential component of evaluating potential modified risk tobacco products is to determine how consumers use the product and resulting effects on biomarkers of toxicant exposure. \\ Study design Cigarette smokers $(n=391)$ recruited in Minnesota and Oregon were randomised to either snus or $4 \mathrm{mg}$ nicotine gum for 12 weeks. Participants were instructed to completely switch from cigarettes to these products. Urine samples were collected to analyse for carcinogenic tobacco-specific nitrosamine metabolites (4-(methylnitrosamino)-1-(3-pyridyl)-1-butanol and $\mathrm{N}^{\prime}$-nitrosonornicotine and their glucuronides) and nicotine metabolites (total cotinine and nicotine equivalents) levels.}

Results Of the 391 participants randomised, 52.9\% were male, the mean $\pm S D$ age was $43.9 \pm 12.5$ years, baseline number of cigarettes/day was $18.0 \pm 6.5$ and Fagerstrom Test for Nicotine Dependence score was 5.1 \pm 2.0 . The mean \pm SD number of snus pouches used/week at week 6 prior to tapering was $39.1 \pm 24.0$ and nicotine gum pieces used was $37.6 \pm 26.3$. Dual use of cigarettes and these products were observed in $52.9 \%$ and $58.2 \%$ of those assigned to snus and nicotine gum, respectively, at week 12. The end of treatment biochemically verified (carbon monoxide, $\mathrm{CO}<6 \mathrm{ppm}$ ) 7-day avoidance of cigarettes was $21.9 \%$ in the snus group and $24.6 \%$ in the nicotine gum group. Toxicant exposure in the nicotine gum group was significantly less when compared to snus.

Conclusions Snus performed similarly to nicotine gum in cigarette smokers who were interested in completely switching to these products, but was associated with less satisfaction and greater toxicant exposure than nicotine gum.

Trial registration number NCT: 00710034.

\section{INTRODUCTION}

In the USA and elsewhere, a low-nitrosamine smokeless tobacco known as snus is promoted as a complete or partial substitute for smoking. Differences in disease risk between cigarettes and snus have led some public health scientists to believe that if smokers completely switched to snus, then reduced tobacco-related mortality and morbidity would likely ensue. ${ }^{1-5}$ For example, the significant reduction in smoking among Swedish men leading to reductions in lung cancer, cardiovascular and all causes mortality, compared to other European Union countries, ${ }^{2}{ }^{6}$ has been attributed to substitution of cigarettes with snus. Smokers who switch to snus appear to have similar risks for cancer and cardiovascular disease as those who quit tobacco. ${ }^{7}$

Furthermore, several cross-sectional survey studies conducted in Scandinavia ${ }^{2} \quad 8 \quad 9-11$ and the USA $^{12}$ show that smokers who have ever used or used snus or snuff daily have a higher probability of quitting smoking than non-snus or non-snuff users. Survey studies conducted in Scandinavia ${ }^{9} 10^{13}$ and USA ${ }^{14}$ also show that snus or snuff, compared to medicinal nicotine, is more frequently used and/or leads to greater smoking cessation success, particularly among men.

Cross-sectional studies, however, do not distinguish whether or not the findings reflect differences in the characteristics of the population who use snus to quit smoking or the effects of the products themselves. A randomised clinical trial would help determine if snus compared to medicinal nicotine leads to higher rates of stopping smoking as a result of complete switching or a greater reduction in smoking and consequent reduction in exposure to harmful constituents. Besides a small pilot study that we conducted ${ }^{15}$ no such clinical trial has been reported in the literature.

The primary goal of this study was to compare snus versus nicotine gum on the extent to which smokers can completely switch to these products, the pattern of product use and effects on biomarkers of exposure. The secondary goals were to compare the effects of both products on withdrawal symptom relief, product evaluation and adverse events.

\section{METHODS}

\section{Participant recruitment}

Cigarette smokers interested in completely switching to snus or nicotine gum were recruited from Minneapolis/St Paul, Minnesota, and Eugene, Oregon, between May 2010 and May 2013, using internet and local media advertisements. Participants were followed through June 2014. Interested smokers who telephoned the research clinics were briefly informed about the study and screened for eligibility. Eligibility criteria included: (1) 18-70 years old; (2) smoking at least 10 cigarettes daily for the past year, (3) in good physical and mental health (no unstable or untreated medical or psychiatric condition); (4) no contraindications for medicinal nicotine; (5) no regular use 
of other nicotine or tobacco products; and (6) if female, not pregnant or nursing. Eligible participants attended the research clinic for an orientation visit, provided informed consent and engaged in more thorough screening, including assessment of their medical and tobacco use history, and nicotine dependence, using the Fagerstrom Test for Nicotine Dependence, ${ }^{16}$ and pregnancy testing. This study was approved by each site's Institutional Review Board, and a Data and Safety Monitoring Board (DSMB) met annually to monitor study progress and adverse events.

\section{Products}

The oral tobacco product chosen was Camel snus (Winterchill and Robust, 2.5 and $2.6 \mathrm{mg}$ nicotine/pouch, respectively, distributed by Reynolds American Inc). These snus products were chosen because of the higher levels of unprotonated nicotine in them compared to other US manufactured snus products and prior research showing that suppression of smoking is greater with oral non-combusted products with higher nicotine levels. ${ }^{17}$ Participants who experienced adverse effects from these doses were provided Frost or Mellow (1.5 and $1.3 \mathrm{mg}$ nicotine/pouch, respectively). A Swedish snus product with even higher levels of nicotine may have been preferable to compare with the Swedish experience. However, our prior preference study showed that no smoker chose the Swedish snus (General Snus). ${ }^{17}$ Nicotine gum (4 mg Nicorette distributed by GlaxoSmithKline) was chosen as the medicinal nicotine product, and participants who experienced adverse effects were down-titrated to $2 \mathrm{mg}$ nicotine gum.

\section{Study design}

Participants were informed that the study examined the effects of snus versus nicotine gum on smoking behaviour and potential health effects. During an initial 1-week baseline data collection, participants reported the number of cigarettes and symptoms associated with withdrawal (Minnesota Nicotine Withdrawal Scale, MNWS ${ }^{18}{ }^{19}$ ) using an Interactive Voice Response (IVR) system at the end of each day. Other baseline measures were collected at the clinic visit (see below).

After the baseline period, participants were randomised to one of the two treatment conditions for 12 weeks. Randomisation lists (separate for each site) used block sizes of 10. In both conditions, participants were encouraged to use only the assigned product and at least 6-8 pieces a day for about 30 min each or optimally every $1-2 \mathrm{~h}$, and more if necessary. Per instructions described for nicotine gum, all participants (regardless of randomisation group) were advised to reduce consumption by half during weeks $7-9$ and three-quarters between weeks $10-12$ to minimise the risk of persistent use or withdrawal from the products when they were no longer provided. Although any non-assigned tobacco or medicinal product use was discouraged, accurate self-report was stressed.

After product assignment, participants returned to the clinic weekly for 2 weeks and bi-weekly for the remaining 10 weeks. At the clinic visits, participants were asked to return all unused product (with the amount used and returned logged in our records) and new products were dispensed, outcome measures collected and brief 10 min standardised behavioural and compliance counselling was provided. The topics covered in the session were based on the Clearing the Air treatment manual ${ }^{20}$ and provided to each participant. Trained counsellors were given a worksheet that described the topics to be covered for each session. Total number of clinic visits was 8 with one phone call at week 10. Follow-up sessions occurred at 13 and 26 weeks from the onset of treatment, with two follow-up calls at weeks
19 and 39 (not included in the analysis). Participants were reimbursed a total of $\$ 360$ for visit attendance and blood draws.

\section{Measures}

Throughout treatment, participants reported product use and any cigarettes smoked on a daily basis using the IVR system. Other measures collected at the baseline and treatment clinic visits included the past week's MNWS, adverse events, vitals and alveolar carbon monoxide (CO). Responses to products were measured using Product Evaluation Scale (Weeks 1, 4 and 12), ${ }^{21}$ a 7-point Likert-type scale modified from the Cigarette Evaluation Scale. ${ }^{22}$ Scale scores addressed four factors: reflecting product satisfaction, psychological reward, sensation in mouth and aversion. ${ }^{23}$

Biomarkers were collected at baseline and week 4 (to maximise the number of data points, prior to relapse or drop-outs). Biomarkers included measures of nicotine exposure: total cotinine $^{24}$ and total nicotine equivalents (the sum of total nicotine, total cotinine and total 3 'hydroxycotinine, TNE ${ }^{25}$ In addition, biomarkers included measures of tobacco-specific carcinogens: (1) urinary 4-(methylnitrosamino)-1-(3-pyridyl)-1-butanol and its glucuronides (total NNAL), ${ }^{26}$ which are metabolites of 4-(methylnitrosamino)-1-(3-pyridyl)-1-butanone (NNK) and (2) $N^{\prime}$-nitrosonornicotine (NNN) and its glucuronides (total $\mathrm{NNN}),{ }^{27}$ which reflect the uptake of NNN.

At follow-up, 26 weeks after start of treatment, smoking abstinence and use of any other tobacco or medicinal nicotine products were assessed using time line follow-back, ${ }^{28}$ and biochemical verification was obtained.

\section{Sample size calculation}

The planned sample size for this study was 400 participants, powered to detect differences between treatment groups in the point prevalence (7-day cigarette avoidance) at the completion of treatment (week 12). Group sample sizes of 200 in each group would achieve at least $80 \%$ power to detect an absolute difference between 7-day cigarette avoidance rates of $10 \%$, if avoidance rates are $12 \%$ and $22 \%$, using nicotine gum and snus, ${ }^{9}$ respectively, using a two-sided $\mathrm{Z}$ test and significance level of 0.05 .

\section{Analytic approach}

Participants' baseline characteristics were compared by product group (nicotine gum vs snus). Discrete variables were analysed using Pearson's $\chi^{2}$ test or Fisher's exact test. Continuous variables were analysed using $t$ tests and Wilcoxon Rank Sum tests as appropriate.

We conducted an intention-to-treat analysis. Biomarkers of exposure were analysed on the natural $\log$ scale to ensure normality and comparisons between baseline and week 4 were conducted using repeated measures linear regression models. All other continuous outcomes with repeated measures from baseline through treatment were analysed using linear mixed models with fixed effects for site, product, week, interaction between product and week, and a random effect for participant. Least squares means and 95\% CIs are presented unless otherwise noted. The differences in the 7-day point prevalence and continuous cigarette avoidance at weeks 12 and 26, or use of any nicotine-containing product at week 26 , between product groups, were evaluated using Pearson's $\chi^{2}$ tests. Study drop-outs were assumed to have started smoking unless otherwise noted. Smoking avoidance was verified using CO levels $(<6 \mathrm{ppm})$ and avoidance of all nicotine-containing products was verified using cotinine $(<35 \mathrm{ng} / \mathrm{mL})$. A sensitivity analysis was performed to 
confirm that the results were similar when including only participants with follow-up data (as compared to the intention-to-treat analysis), and the conclusions were the same.

Data were analysed using SAS V.9.3 (Cary, North Carolina, USA), and $\mathrm{p}$ values $<0.05$ were considered statistically significant.

\section{RESULTS}

\section{Participant characteristics}

With approval from the DSMB, recruitment was stopped early due to time constraints; a total of 391 participants were enrolled in the study. Figure 1 shows the disposition of the participants in the study and table 1 provides baseline demographic and tobacco use history information. No significant differences were observed by product group. However, site differences were observed with participants in Minnesota being older (46.5 \pm 11.7 vs $41.5 \pm 12.8, \mathrm{p}<0.0001)$ and smoking more cigarettes per day $(19.3 \pm 7.3$ vs $16.9 \pm 5.5, \mathrm{p}=0.0003)$.

\section{Product use}

Based on the IVR, the proportion of participants using the study products did not statistically significantly differ between assigned products at any week during the treatment period; use ranged from 99\% for snus and 100\% for gum at week 1 and gradually declined to $80 \%$ for snus and $87 \%$ for gum at week 12. The lowest proportion reporting using each study product was at week 11 for gum (82\%) and week 12 for snus $(80 \%)$. Figure 2A shows the mean product use per week. Although significant week effects were observed $(\mathrm{p}<0.0001)$, no other significant differences were observed.

Table 2 shows the proportion of participants using only the study product, smoking cigarettes plus study product, smoking cigarettes only and using neither study product nor cigarettes at week 6 (prior to taper) and week 12 (end of treatment). No significant differences were observed across study products. Use of other products during the treatment was minimal; less than $5 \%$ of participants reported use of cigars, e-cigarettes, smokeless tobacco or other nicotine replacement therapies.

Focusing on dual use, the proportion of dual users varied during treatment for snus (53-77\%) and nicotine gum (48$79 \%$ ), with the highest percentage occurring earlier in the experimental period. Figure $2 \mathrm{~B}$ shows the mean number of usual brand cigarettes used per week. Significant effects were only observed for site $(\mathrm{p}<0.0001$; greater in Oregon than Minnesota) and study week $(p=0.019)$. When correlating the extent of product use with cigarettes smoked, during week 1, more cigarette use was weakly associated with lower nicotine gum and snus use $(\mathrm{r}=-0.17, \mathrm{p}=0.018$ and $\mathrm{r}=-0.27$,

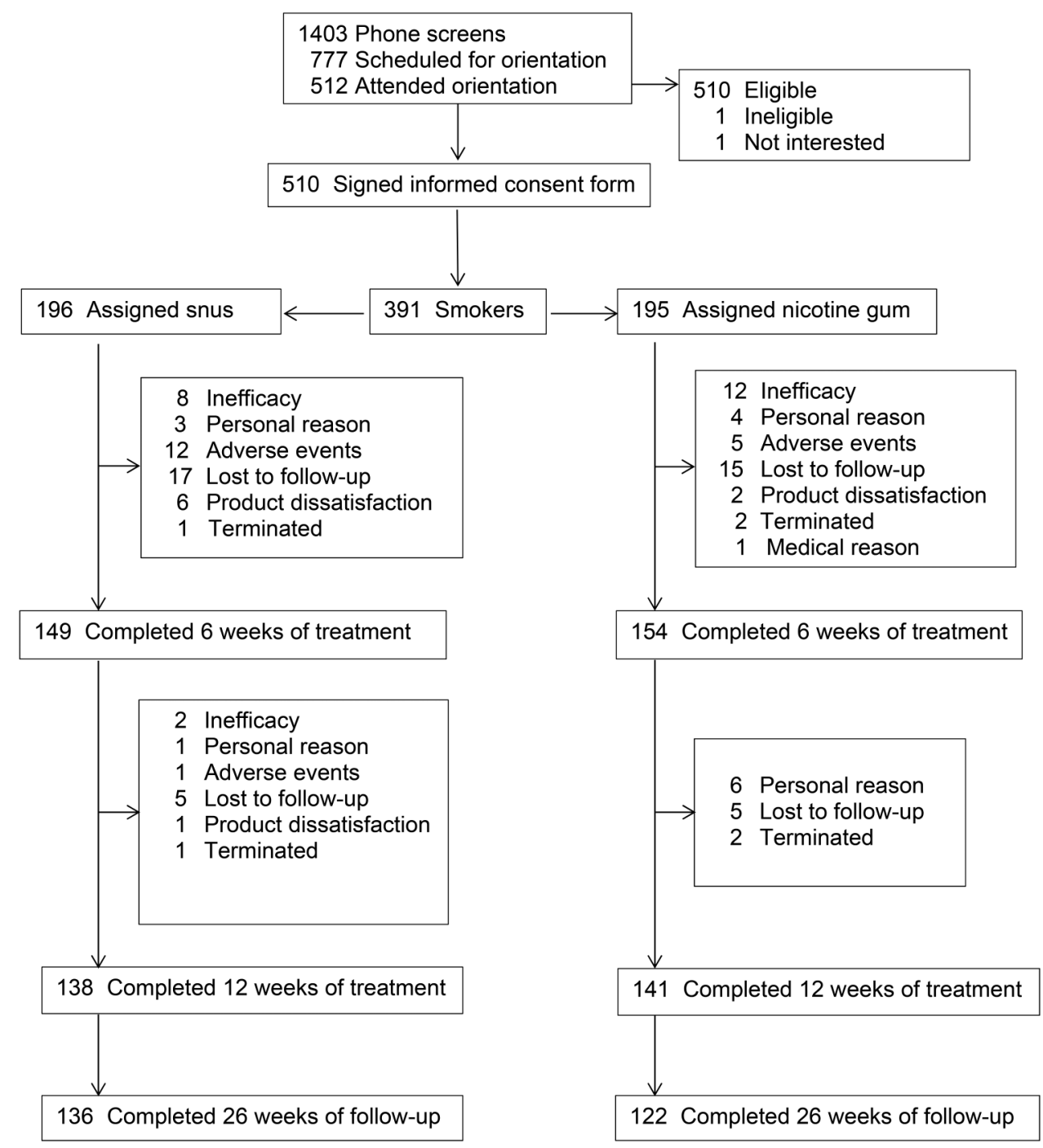

Figure 1 Flow of participants in study. 
Table 1 Baseline demographics and smoking history (percent or mean $\pm S D)$ of participants $(N=391)$ by treatment group

\begin{tabular}{|c|c|c|c|c|c|c|}
\hline \multirow[b]{2}{*}{ Age (years) } & \multicolumn{2}{|c|}{ Overall } & \multicolumn{2}{|c|}{ Nicotine gum } & \multicolumn{2}{|c|}{ Camel snus } \\
\hline & 391 & $43.9 \pm 12.5$ & 195 & $44.7 \pm 12.5$ & 196 & $43.2 \pm 12.5$ \\
\hline Female & 184 & $47.1 \%$ & 95 & $48.7 \%$ & 89 & $45.4 \%$ \\
\hline Non-Hispanic whites & 320 & $81.8 \%$ & 165 & $84.6 \%$ & 155 & $79.1 \%$ \\
\hline \multicolumn{7}{|l|}{ Education } \\
\hline Some high school & 25 & $6.4 \%$ & 11 & $5.6 \%$ & 14 & $7.1 \%$ \\
\hline High school graduate or equivalent & 107 & $27.4 \%$ & 52 & $26.7 \%$ & 55 & $28.1 \%$ \\
\hline Some college/2-year degree & 192 & $49.1 \%$ & 99 & $50.8 \%$ & 93 & $47.5 \%$ \\
\hline College graduate/4-year degree & 51 & $13.0 \%$ & 25 & $12.8 \%$ & 26 & $13.3 \%$ \\
\hline Graduate & 16 & $4.1 \%$ & 8 & $4.1 \%$ & 8 & $4.1 \%$ \\
\hline Cigarettes per day & 391 & $18.0 \pm 6.5$ & 195 & $18.3 \pm 6.8$ & 196 & $17.8 \pm 6.2$ \\
\hline Age smoking first cigarette (years) & 386 & $14.3 \pm 4.2$ & 194 & $14.4 \pm 4.3$ & 192 & $14.2 \pm 4.1$ \\
\hline Age becoming a regular smoker (years) & 386 & $17.6 \pm 4.8$ & 194 & $17.8 \pm 5.3$ & 192 & $17.3 \pm 4.1$ \\
\hline Ever tried smokeless tobacco & 171 & $44.4 \%$ & 79 & $40.7 \%$ & 92 & $48.2 \%$ \\
\hline Ever tried nicotine gum & 117 & $29.9 \%$ & 60 & $30.8 \%$ & 57 & $29.1 \%$ \\
\hline \multicolumn{7}{|l|}{ Number of quit attempts } \\
\hline $0-2$ & 140 & $36.3 \%$ & 68 & $35.1 \%$ & 72 & $37.5 \%$ \\
\hline $3-5$ & 141 & $36.5 \%$ & 74 & $38.1 \%$ & 67 & $34.9 \%$ \\
\hline $6-10$ & 57 & $14.8 \%$ & 26 & $13.4 \%$ & 31 & $16.2 \%$ \\
\hline $11-20$ & 48 & $12.4 \%$ & 26 & $13.4 \%$ & 22 & $11.5 \%$ \\
\hline FTND & 390 & $5.1 \pm 2.0$ & 195 & $5.0 \pm 1.9$ & 195 & $5.2 \pm 2.0$ \\
\hline
\end{tabular}

$\mathrm{p}=0.0003)$; this continued for those in the snus group through week $5(\mathrm{r}=-0.21$ to -0.24 , $\mathrm{p}$ values $=0.001-0.006)$. In the gum group, higher cigarette use in the latter weeks (9-12) was weakly associated with higher product use $(\mathrm{r}=0.18-0.31$, $\mathrm{p}$ values $=0.002-0.029$ ).

\section{Biomarkers of exposure}

For cotinine, significant reductions were observed from baseline to week 4 for nicotine gum and snus (both $\mathrm{p}<0.0001$ ). No significant effects by study product or site were observed at week 4 after adjustment for baseline values. TNE results were similar. For urinary total NNAL, significant reductions were observed from baseline to week 4 for nicotine gum $(\mathrm{p}<0.0001)$, but not snus. Significant differences at week 4 by study product $(p<0.0001)$ were observed; nicotine gum users showing greater change than snus users.

Table 3 shows total NNAL, total cotinine and TNE values for assigned product only or dual users (cigarettes plus assigned product) among those with baseline as well as week 4 values. Comparisons of week 4 values were adjusted for baseline biomarker values and site, and corrected for multiple comparisons. Among product only and dual users, total NNAL was significantly higher among snus versus nicotine gum users $(p<0.001$ and 0.005 , respectively). While no significant differences were observed for the snus only and snus dual users, significantly lower levels of total NNAL were observed in the nicotine gum
Figure 2 Mean (SD) amount of product use $(A)$ and amount of cigarette use among dual users by product group (B).
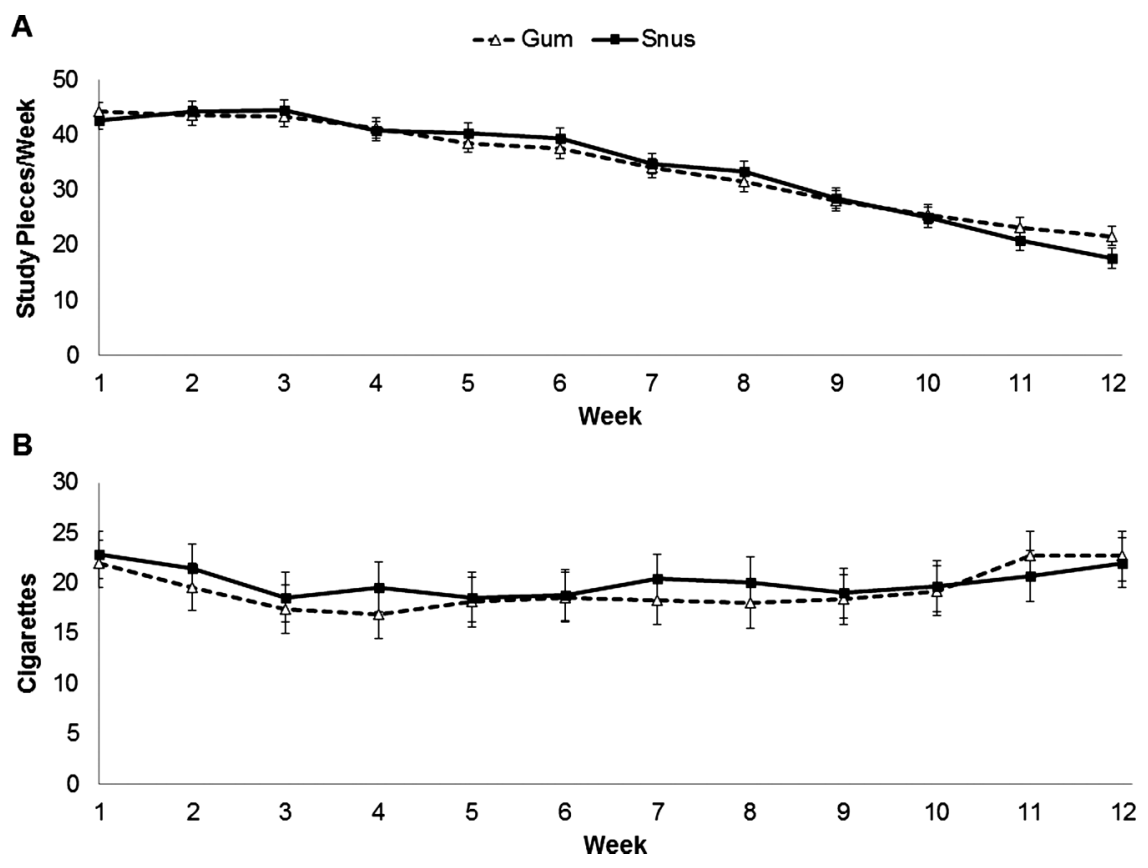
Table 2 Proportion of participants using different products during study product assignment

\begin{tabular}{|c|c|c|c|c|c|c|c|c|}
\hline & \multicolumn{4}{|c|}{ Week 6** } & \multicolumn{4}{|c|}{ Week $12 * * *$} \\
\hline & \multicolumn{2}{|c|}{$\begin{array}{l}\text { Gum } \\
(\mathrm{N}=153)\end{array}$} & \multicolumn{2}{|c|}{$\begin{array}{l}\text { Snus } \\
(\mathrm{N}=149)\end{array}$} & \multicolumn{2}{|c|}{$\begin{array}{l}\text { Gum } \\
(\mathrm{N}=141)\end{array}$} & \multicolumn{2}{|c|}{$\begin{array}{l}\text { Snus } \\
(N=138)\end{array}$} \\
\hline & $\mathbf{N}$ & $\begin{array}{l}\text { Per } \\
\text { cent }\end{array}$ & $\mathbf{N}$ & $\begin{array}{l}\text { Per } \\
\text { cent }\end{array}$ & $\mathrm{N}$ & $\begin{array}{l}\text { Per } \\
\text { cent }\end{array}$ & $N$ & $\begin{array}{l}\text { Per } \\
\text { cent }\end{array}$ \\
\hline Product only & 56 & 36.6 & 56 & 37.6 & 40 & 28.4 & 37 & 26.8 \\
\hline Cigarette+product use & 79 & 51.6 & 82 & 55.0 & 82 & 58.2 & 73 & 52.9 \\
\hline Cigarette only & 9 & 5.9 & 5 & 3.4 & 6 & 4.3 & 16 & 11.6 \\
\hline $\begin{array}{l}\text { Neither cigarette nor } \\
\text { product use }\end{array}$ & 9 & 5.9 & 6 & 4.0 & 13 & 9.2 & 12 & 8.7 \\
\hline
\end{tabular}

only versus gum dual users $(\mathrm{p}=0.001)$. Although no other comparisons were statistically significant for total cotinine, significantly lower TNE levels for snus only versus dual users $(\mathrm{p}=0.042)$ were observed.

Owing to costs, for total NNN, a random selection of participants who reported using $>30$ pieces/week of the assigned product during weeks 2-4 were selected, and dual users reported reducing their smoking 35-85\% at week 4 compared to baseline (table 3). Significantly lower urinary total NNN were observed among those who only used nicotine gum compared to snus $(p<0.0001)$, but no significant differences were observed across dual users. Nicotine gum only users had significantly lower total NNN compared to gum dual users $(p=0.008)$, but no differences were observed between snus only compared to snus dual users.

\section{Effect on subjective responses: withdrawal and product evaluation}

For withdrawal symptoms (craving excluded), although significant study week effects were observed $(p<0.0001)$, with a significant increase occurring from Baseline to week 1 $(\mathrm{p}<0.0001)$, no significant product, or product by study week effects, were evident. There was a statistically significant difference by site $(p=0.021)$, with those participants in Minnesota experiencing lower withdrawal. In addition, craving significantly decreased over time $(\mathrm{p}<0.0001)$, though it did not differ significantly by product or site.

For the product Satisfaction and Psychological Reward scales, significant study week $(\mathrm{p}<0.0001$ for both scales), product $(\mathrm{p}<0.0001$ and $\mathrm{p}=0.009$, respectively) and product by study week effects $(p=0.001$ and $p=0.005$, respectively), were observed. Usual brand cigarettes were more satisfying and psychologically rewarding than either of the products $(p<0.0001$ both products and scales, respectively), and those assigned to nicotine gum reported greater satisfaction and psychological reward than snus users. Site differences were also observed $(p \leq 0.0001)$, with those users in Minnesota reporting higher scale scores. Likewise, for Sensation in Mouth, study week $(\mathrm{p}<0.0001)$, product $(\mathrm{p}<0.0001)$ and product by study week $(\mathrm{p}<0.0001)$, effects were statistically significant, though site was not. Gum users reported higher scores on this scale than snus users, and usual brand cigarettes were rated lower than either product $(\mathrm{p}<0.0001$ and $\mathrm{p}=0.007$, respectively), indicating that mouth sensation may not be as highly associated with cigarette smoking. Although no product effects were found for Aversion, study week effects $(p<0.0001)$ showed significantly higher scores for the study products compared to usual brand cigarettes and a significant site effect $(p=0.003)$, with those in Minnesota reporting greater aversion to the products.

The adverse events that were experienced were typical of those found with nicotine gum, and only a few differences were observed between the two study products (see online supplemental table). It appears that gum and snus led to experiences of dry mouth, excessive salivation, dizziness, light-headedness (snus users), nausea, stomach aches, sore jaw, belching, hiccups, sore throat, mouth sores and, interestingly, a reduction in anxiety, and for snus users, a reduction in reported headaches. Significant differences were observed between snus and nicotine gum for excessive salivation $(\mathrm{p}<0.0001)$, headaches $(\mathrm{p}=0.022)$ and mouth sores $(\mathrm{p}=0.020)$; more snus users experienced

Table 3 Urinary biomarkers by treatment and study product only or dual use of study product and cigarettes at week 4

\begin{tabular}{|c|c|c|c|c|c|c|c|c|}
\hline & \multicolumn{4}{|c|}{ Nicotine gum } & \multicolumn{4}{|c|}{ Snus } \\
\hline & \multicolumn{2}{|c|}{ Baseline } & \multicolumn{2}{|c|}{ Week 4} & \multicolumn{2}{|c|}{ Baseline } & \multicolumn{2}{|c|}{ Week 4} \\
\hline & $\mathrm{N}^{*}$ & Mean (SD) & $\mathrm{N}^{*}$ & Mean (SD) & $\mathrm{N}^{*}$ & Mean (SD) & $\mathrm{N}^{*}$ & Mean (SD) \\
\hline \multicolumn{9}{|c|}{ Total NNAL (pmol/mg creatinine) } \\
\hline Study product only $\dagger$ & 58 & $1.39(1.04)$ & 58 & $0.30(0.39)$ & 52 & $1.28(0.94)$ & 52 & $1.34(1.42)$ \\
\hline Dual users & 96 & $1.58(1.19)$ & 96 & $1.11(1.00)$ & 96 & $1.47(1.55)$ & 96 & $1.55(1.67)$ \\
\hline \multicolumn{9}{|l|}{ Total cotinine $(\mathrm{ng} / \mathrm{mL})$} \\
\hline Study product only $\dagger$ & 59 & 3481 (1839) & 59 & $2052(2342)$ & 53 & 3385 (1672) & 53 & $2152(2005)$ \\
\hline Dual users & 97 & $3572(2297)$ & 97 & $2838(2229)$ & 100 & 3359 (2145) & 100 & 3079 (2398) \\
\hline \multicolumn{9}{|c|}{ Total nicotine equivalent $†(\mathrm{nmol} / \mathrm{mL})$} \\
\hline Study product only $\dagger$ & 59 & $63.6(40.9)$ & 59 & $36.0(42.1)$ & 53 & $59.5(32.3)$ & 53 & $35.6(31.0)$ \\
\hline Dual users & 97 & $65.8(42.1)$ & 97 & $51.2(41.9)$ & 100 & $66.2(49.3)$ & 100 & $55.7(43.0)$ \\
\hline \multicolumn{9}{|c|}{ Total NNN* (pmol/mg creatinine) } \\
\hline Study product only $†$ & 24 & $0.06(0.07)$ & 24 & $0.01(0.01)$ & 18 & $0.06(0.06)$ & 18 & $0.06(0.07)$ \\
\hline Dual users & 25 & $0.09(0.09)$ & 25 & $0.05(0.05)$ & 23 & $0.13(0.22)$ & 23 & $0.11(0.10)$ \\
\hline
\end{tabular}

* Lower number of participants is due to analysis of a subset of participants.

tCarbon monoxide (CO) verified ( $<6 \mathrm{ppm})$. 
excessive salivation and mouth sores but fewer experienced headaches compared to nicotine gum users.

\section{Cigarette and product use at the end of treatment and follow-up}

In the intent-to-treat analysis, at the end of the treatment phase (week 12), no significant differences were observed for 7-day cigarette avoidance between nicotine gum and snus $(24.6 \%$ vs $21.9 \%$, respectively) or for continuous cigarette avoidance from week 2 to end of treatment $(9.7 \%$ vs $5.6 \%$, respectively). Similarly, at week 26 , no significant differences between nicotine gum and snus were observed for 7-day cigarette avoidance (15.4\% vs $11.2 \%$, respectively) and continuous cigarette avoidance $(5.1 \%$ vs $2.6 \%$, respectively), or for point prevalence (9.7\% vs $5.6 \%$, respectively) and continuous (3.6\% vs $2.0 \%$, respectively) avoidance of all nicotine products. There were no statistically significant differences by site for any of these outcomes.

With regard to continued product use, among those assigned to nicotine gum and participated at the 26 week follow-up, approximately $6.0 \%$ self-reported gum use only and $6.8 \%$ reported gum and cigarettes use. The rates were 14.9\% and $11.6 \%$, respectively, for snus use among those assigned to snus. The distribution of these rates was significantly different between snus and gum $(p=0.006)$, with higher rates of continued snus use among those assigned to this product.

\section{DISCUSSION}

The results showed no significant differences between those assigned to medicinal nicotine vs snus in amount of product use, levels of cotinine attained, the extent to which the product substituted for smoking and rates of avoidance of cigarettes or any nicotine containing products. Furthermore, there were no differences in suppression of withdrawal from cigarettes. However, the nicotine gum users reported more satisfaction and psychological reward from the product, experienced less carcinogen exposure during the time of peak use, and had fewer participants who continued product use compared to the snus users. These findings suggest that snus performs no better than nicotine gum as a cigarette substitute, has less appeal, is more toxic and is associated with higher rates of prolonged use.

The results from the current study replicate our prior pilot study, which showed that snus, at doses similar to nicotine gum, is no better than medicinal nicotine in the extent to which complete substitution occurred. ${ }^{15}$ Similar to the present study, Kotlyar et $a l^{15}$ showed higher levels of urinary total NNAL when smokers substituted snus compared to medicinal nicotine for cigarettes. However, while the prior study showed a significant reduction in total NNAL when switching to snus, in the current study, no reduction was observed. This difference across studies may be attributed to the roughly threefold increase in NNK/pouch between 2010 and 2012-2013 (from 0.15 to $0.49 \mu \mathrm{g} /$ pouch). With regard to NNN, in the Kotlyar et al, ${ }^{15}$ study no significant reduction was found when smokers switched to snus, which was similar to our findings from the present study. Furthermore, significant reductions in total NNN were observed with nicotine gum use. However, unlike the Kotlyar study, which observed no group differences, the present study observed greater reductions in total $\mathrm{NNN}$ in nicotine gum users, potentially due to the analysis of a subset of the participants in the current study or a larger sample size.

Contrary to the results from survey studies in Scandinavian countries, in this study, snus was associated with less positive subjective responses compared to medicinal nicotine. This finding is concordant with other North American clinical and survey studies showing medicinal nicotine products being preferred over oral tobacco products such as snus or dissolvable tobacco products. ${ }^{29-31}$ On the other hand, in a brief clinical study conducted in New Zealand, heavy smokers reported greater preference for Zonnic (an oral nicotine sachet of $4 \mathrm{mg}$ of nicotine bound to beads) and Swedish snus, over nicotine gum, for use in quitting or reducing cigarettes. ${ }^{32}$

Unlike survey studies in Scandinavian countries, which have demonstrated high interest in snus among men, US surveys show relatively less interest in snus. In one survey, although $29.9 \%$ of male smokers reported ever trying snus, only $4.2 \%$ reported current use. Current use was negligible in former smokers. The authors concluded that the low rate of adoption of snus in the US market signifies that this product is unlikely to be a significant harm reduction agent or to lead to public health harm. ${ }^{33}$ Other survey studies have also demonstrated low interest in the use of snus in the USA. ${ }^{34}$ Perhaps the lack of US interest in snus as a substitute for cigarettes is why recruitment for this study took longer than anticipated.

The results also show that a substantial number of smokers motivated to switch completely to an alternative product become dual users during the treatment period. This finding could be related to the low levels of free nicotine in our chosen product, the slower rate of absorption relative to cigarettes and the lack of the sensory aspects of smoking, attributes which lead to being a poor substitute for cigarettes. Human laboratory and short-term product cross-over studies have demonstrated that although medicinal nicotine and snus sold in the US suppressed cigarette abstinence-induced craving, usual brand cigarettes led to substantially greater suppression of craving. Furthermore, acceptability of these products was substantially lower than usual brand cigarettes and, in one study, was more in line with the sham smoking condition, leading the authors to conclude that these products are unlikely to completely substitute for cigarettes. $^{36} 37$ In one study, even when smokers were offered a Swedish snus product with a high nicotine dose, no one chose this product for use during smoking cessation after sampling it. ${ }^{17}$

The trend toward more favourable responses to nicotine gum points to two observations. First, the use of $4 \mathrm{mg}$ medicinal nicotine as a substitute for cigarette smoking and a harm reduction agent should be considered. More recently, an application for Swedish snus as a modified risk tobacco product has been submitted (Docket ID: FDA-2014-N-1051), yet medicinal nicotine gum more clearly results in reduced exposures to toxicants. Second, other minor tobacco alkaloids have been considered as potentially contributing to the reinforcing effects of tobacco products, ${ }^{38} 39$ the results from this study suggest that these constituents may or may not play an important role in tobacco self-administration or response. That is, the amount of self-administration was similar across products (perhaps due to instructions for amount of use), but sustained use was higher with snus. Rat studies tend to show smokeless tobacco extracts do not enhance nicotine effects compared to similar doses of nicotine alone. ${ }^{40}$

There are several limitations to this study: (1) potential lack of generalisability to a general population of smokers because we examined smokers interested in trying an alternative product in a clinic setting, (2) testing only one snus product, which has lower levels of nicotine and higher TSNA than some of the Swedish snus products, (3) encouragement to use a specified number of pieces of each of the products; (4) implementation of a tapering period, which might have constrained substitution behaviour; and (5) not examining the data by 
gender (eg, men as opposed to women may respond more positively to snus).

Nonetheless, these results suggest that, in the USA, snus may not succeed in substituting for cigarettes because of lack of interest and appeal, even when compared to medicinal nicotine. The differences in responses to snus-like products across different countries and even different sites emphasise the need to take into account the cultural context in which a product is being marketed and used. Because medicinal nicotine performed no differently or even better on some outcome variables than the snus that we tested, and had substantially less carcinogen exposure, even when this snus product alone is compared to dual nicotine gum and cigarette users, it is prudent to recommend medicinal nicotine over snus, particularly in the USA, for those who want to reduce or completely switch to another product.

\section{What this paper adds}

What is already known on this topic

- Switching from cigarettes to snus products has been described as a harm reduction method for smokers who are unable or unwilling to quit smoking.

- In Sweden, switching from cigarettes to snus has resulted in a significant reduction in tobacco-related health risks.

What important gaps in knowledge exist on this topic

- So far, no clinical trial has examined the effects of snus versus medicinal nicotine on pattern of product use, exposure biomarkers, subjective responses and the extent of complete switching.

- Furthermore, the generalisability of results from Sweden to other countries is unknown.

\section{What this study adds}

- In this US-based study, US-marketed snus performed no better than nicotine gum in cigarette smokers who were interested in completely switching to these products, but was associated with greater toxicant exposure and less satisfaction than nicotine gum.

- Generalising harm reduction effects observed in Sweden to another country may be limited.

Correction notice This article has been corrected since it was published Online First. In Table 3, the unit of measure for total cotinine has been corrected to ' $\mathrm{ng} / \mathrm{mL}$ ' from ' $\mathrm{nmol} / \mathrm{mL}$ '.

Contributors DKH planned and provided oversight for the study, directed the data analysis, wrote the initial draft and submitted the manuscript. HS helped plan the study and provided oversight at the Oregon site. AA and BB implemented the study at Minnesota and Oregon sites, respectively. RIV conducted the data analysis and wrote parts of the manuscript. JJ contributed to the design of the study and provided oversight of the regulatory aspects of the study. SEM, SC and SSH provided guidance and conducted the biomarker analyses. All authors contributed to the revision of the manuscript and approved of its contents.

Funding National Cancer Institute R01 CA135884 (D Hatsukami), P30 CA077598 and UL1TR000114.

Competing interests None declared.

Patient consent Obtained.

Ethics approval Institutional Review Board.

Provenance and peer review Not commissioned; externally peer reviewed.

Data sharing statement We will make de-identified data and associated documentation available to users only under a data-sharing agreement that provides for: (1) a commitment to using the data only for research purposes and a commitment to not identify any individual participant; (2) a commitment to securing the data using appropriate computer technology; and (3) a commitment to destroying or returning the data after analyses are completed.

Open Access This is an Open Access article distributed in accordance with the terms of the Creative Commons Attribution (CC BY 4.0) license, which permits others to distribute, remix, adapt and build upon this work, for commercial use, provided the original work is properly cited. See: http://creativecommons.org/ licenses/by/4.0/

\section{REFERENCES}

1 Fagerstrom KO, Schildt EB. Should the European Union lift the ban on snus? Evidence from the Swedish experience. Addiction 2003:98:1191-5.

2 Foulds J, Ramstrom L, Burke $M$, et al. Effect of smokeless tobacco (snus) on smoking and public health in Sweden. Tob Control 2003;12:349-59.

3 Levy DT, Mumford EA, Cummings KM, et al. The relative risks of a low-nitrosamine smokeless tobacco product compared with smoking cigarettes: estimates of a panel of experts. Cancer Epidemiol Biomarkers Prev 2004;13:2035-42.

4 Rodu B, Cole P. Tobacco-related mortality. Nature 1994;370:184.

5 Bates C, Fagerstrom K, Jarvis MJ, et al. European Union policy on smokeless tobacco: a statement in favour of evidence based regulation for public health. Tob Control 2003;12:360-7.

6 Ramstrom L, Wikmans T. Mortality attributable to tobacco among men in Sweden and other European countries: an analysis of data in a WHO report. Tob Induc Dis 2014;12:14.

7 Lee PN. The effect on health of switching from cigarettes to snus - a review. Regul Toxicol Pharmacol 2013:66:1-5.

8 Gilljam H, Galanti MR. Role of snus (oral moist snuff) in smoking cessation and smoking reduction in Sweden. Addiction 2003;98:1183-9.

9 Lund KE, McNeill A, Scheffels J. The use of snus for quitting smoking compared with medicinal products. Nicotine Tob Res 2010;12:817-22.

10 Scheffels J, Lund KE, McNeill A. Contrasting snus and NRT as methods to quit smoking: an observational study. Harm Reduct J 2012;9:10.

11 Furberg $\mathrm{H}$, Bulik CM, Lerman C, et al. Is Swedish snus associated with smoking initiation or smoking cessation? Tob Control 2005;14:422-4.

12 Tomar SL. Snuff use and smoking in US men-Implications for harm reduction. Am J Prev Med 2002;23:143-9.

13 Ramstrom LM, Foulds J. Role of snus in initiation and cessation of tobacco smoking in Sweden. Tob Control 2006;15:210-14.

14 Rodu B, Phillips CV. Switching to smokeless tobacco as a smoking cessation method: evidence from the 2000 National Health Interview Survey. Harm Reduct J 2008;5:18.

15 Kotlyar M, Hertsgaard LA, Lindgren BR, et al. Effect of oral snus and medicinal nicotine in smokers on toxicant exposure and withdrawal symptoms: a feasibility study. Cancer Epidemiol Biomarkers Prev 2011;20:91-100.

16 Heatherton TF, Koslowski LT, Frecker RC, et al. The Fagerström Test for nicotine dependence: a revision of the Fagerström Tolerance Questionnaire. $\mathrm{Br} J$ Addict 1991;86:1119-27.

17 Hatsukami DK, Jensen J, Anderson A, et al. Oral tobacco products: preference and effects among smokers. Drug Alcohol Depend 2011;118:230-6.

18 Hughes JR, Hatsukami D. Signs and symptoms of tobacco withdrawal. Arch Gen Psychiatry 1986;43:289-94.

19 Hughes JR, Hatsukami DK. The nicotine withdrawal syndrome: a brief review and update. Int J Smoking Cessation 1992;1:21-6.

20 National Cancer Institute. Clearing the air. Quit smoking today: U.S. Department of health \& human services. National Institutes of Health, 2011.

21 Hatsukami DK, Zhang Y, O'Connor RJ, et al. Subjective responses to oral tobacco products: scale validation. Nicotine Tob Res 2013;15:1259-64.

22 Westman $E$, Levin E, Rose J. Smoking while wearing the nicotine patch: Is smoking satisfying or harmful? Clin Res 1992;40:871A.

23 Cappelleri JC, Bushmakin AG, Baker CL, et al. Confirmatory factor analyses and reliability of the modified cigarette evaluation questionnaire. Addictive Beh 2007;32:912-23.

24 Murphy SE, Link CA, Jensen J, et al. A comparison of urinary biomarkers of tobacco and carcinogen exposure in smokers. Cancer Epidemiol Biomarkers Prev 2004;13:1617-23.

25 Scherer G, Engl J, Urban M, et al. Relationship between machine-derived smoke yields and biomarkers in cigarette smokers in Germany. Regul Toxicol Pharmacol 2007:47:171-83.

26 Carmella SG, Ming X, Olvera N, et al. High throughput liquid and gas chromatography-tandem mass spectrometry assays for tobacco-specific nitrosamine and polycyclic aromatic hydrocarbon metabolites associated with lung cancer in smokers. Chem Res Toxicol 2013;26:1209-17.

27 Yuan JM, Knezevich AD, Wang R, et al. Urinary levels of the tobacco-specific carcinogen $\mathrm{N}^{\prime}$-nitrosonornicotine and its glucuronide are strongly associated with esophageal cancer risk in smokers. Carcinogenesis 2011;32: 1366-71. 


\section{Research}

28 Sobell LC, Sobell MB. Timeline follow-back. A technique for assessing self-reported alcohol consumption. In: Litten R, Allen J, eds. Measuring alcohol consumption. The Humana Press Inc., 1992:41-69.

29 O'Connor RJ, Norton KJ, Bansal-Travers M, et al. US smokers' reactions to a brief trial of oral nicotine products. Harm Reduct J 2011;8:1.

30 Barrett SP, Campbell ML, Temporale K, et al. The acute effect of Swedish-style snus on cigarette craving and self-administration in male and female smokers. Hum Psychopharmacol 2011;26:58-62.

31 Shiffman S, Gitchell J, Rohay JM, et al. Smokers' preferences for medicinal nicotine vs smokeless tobacco. Am J Health Behav 2007;31:462-72.

32 Caldwell B, Burgess C, Crane J. Randomized crossover trial of the acceptability of snus, nicotine gum, and Zonnic therapy for smoking reduction in heavy smokers. Nicotine Tob Res 2010;12:179-83.

33 Biener L, Roman AM, Mc Inerney SA, et al. Snus use and rejection in the USA. Tob Control Published Online First: 25 Feb 2014. doi:10.1136/tobaccocontrol-2013051342

34 McMillen R, Maduka J, Winickoff J. Use of emerging tobacco products in the United States. J Environ Public Health 2012;2012:989474.
35 King BA, Dube SR, Tynan MA. Current tobacco use among adults in the United States: findings from the National Adult Tobacco Survey. Am J Public Health 2012;102:e93-100.

36 Cobb CO, Weaver MF, Eissenberg T. Evaluating the acute effects of oral, non-combustible potential reduced exposure products marketed to smokers. Tob Control 2010;19:367-73.

37 Blank MD, Eissenberg T. Evaluating oral noncombustible potential-reduced exposure products for smokers. Nicotine Tob Res 2010;12:336-43.

38 Carter LP, Stitzer ML, Henningfield JE, et al. Abuse liability assessment of tobacco products including potential reduced exposure products. Cancer Epidemiol Biomarkers Prev 2009;18:3241-62.

39 Henningfield JE, Hatsukami DK, Zeller $\mathrm{M}$, et al. Conference on abuse liability and appeal of tobacco products: conclusions and recommendations. Drug Alcohol Depend 2011;116:1-7.

40 Harris AC, Tally L, Schmidt CE, et al. Animal models to assess the abuse liability of tobacco products: Effects of smokeless tobacco extracts on intracranial self-stimulation. Drug Alcohol Depend 2015; $147: 60-7$. 